NBER WORKING PAPER SERIES

\title{
MARKET POWER AND PRICE DISCRIMINATION IN THE U.S. MARKET FOR HIGHER EDUCATION
}

\author{
Dennis Epple \\ Richard Romano \\ Sinan Sarpça \\ Holger Sieg \\ Melanie Zaber \\ Working Paper 23360 \\ http://www.nber.org/papers/w23360
NATIONAL BUREAU OF ECONOMIC RESEARCH
1050 Massachusetts Avenue
Cambridge, MA 02138
April 2017

The authors thank Philipp Kirchner, Charles Manski, Derek Neal, Cecilia Rouse, Petra Todd, Ken Wolpin, and seminar participants at various conferences and workshops for comments. We would like to thank the NSF for financial support (NSF SES-1355892). Any opinions, findings, and conclusions or recommendations expressed in this material are those of the authors and do not necessarily reflect the views of the National Science Foundation or the National Center for Education Statistics. The views expressed herein are those of the authors and do not necessarily reflect the views of the National Bureau of Economic Research.

NBER working papers are circulated for discussion and comment purposes. They have not been peerreviewed or been subject to the review by the NBER Board of Directors that accompanies official NBER publications.

(C) 2017 by Dennis Epple, Richard Romano, Sinan Sarpça, Holger Sieg, and Melanie Zaber. All rights reserved. Short sections of text, not to exceed two paragraphs, may be quoted without explicit permission provided that full credit, including (C) notice, is given to the source. 
Market Power and Price Discrimination in the U.S. Market for Higher Education

Dennis Epple, Richard Romano, Sinan Sarpça, Holger Sieg, and Melanie Zaber

NBER Working Paper No. 23360

April 2017

JEL No. H52,I2,L3

\begin{abstract}
The main purpose of this paper is to estimate an equilibrium model of private and public school competition that can generate realistic pricing patterns for private universities in the U.S. We show that the parameters of the model are identified and can be estimated using a semi-parametric estimator given data from the NPSAS. We find substantial price discrimination within colleges. We estimate that a $\$ 10,000$ increase in family income increases tuition at private schools by on average $\$ 210$ to $\$ 510$. A one standard deviation increase in ability decreases tuition by approximately $\$ 920$ to $\$ 1,960$ depending on the selectivity of the college. Discounts for minority students range between $\$ 110$ and $\$ 5,750$.
\end{abstract}

Dennis Epple

Tepper School of Business

Carnegie Mellon University

Posner Hall, Room 257B

Pittsburgh, PA 15213

and NBER

epple@cmu.edu

Richard Romano

University of Florida

Department of Economics

PO Box 117140

Gainesville, FL 32611

richard.romano@warrington.ufl.edu

Sinan Sarpça

Koç University

Department of Economics

Rumelifeneri Yolu, Sariyer

34450 İstanbul

Turkey

ssarpca@ku.edu.tr

\author{
Holger Sieg \\ Department of Economics \\ University of Pennsylvania \\ 3718 Locust Walk \\ Philadelphia, PA 19104 \\ and NBER \\ holgers@econ.upenn.edu \\ Melanie Zaber \\ Heinz College of Public Policy \\ Carnegie Mellon University \\ 5000 Forbes Ave. \\ Pittsburgh, PA 15213 \\ mzaber@cmu.edu
}




\section{Introduction}

The net tuition paid by any two students sitting in the same college classroom is often quite different. ${ }^{1}$ Product differentiation and market segmentation together with idiosyncratic preference shocks can generate market power for private colleges. Private colleges and universities engage in third-degree price discrimination, conditioning institutional financial aid and thus net tuition on student ability, household income, and other characteristics such as minority status. Colleges compete to attract higher ability students and students who increase diversity, while also wanting high income students who might cross-subsidize desirable lower income students. The exercise of market power can be expected to vary across student types. The main purpose of this paper is to estimate an equilibrium model of private and public school competition that can generate realistic pricing patterns for private universities.

Our empirical analysis builds on the model developed in Epple, Romano, Sarpca, and Sieg (2017), in which students differ by income, ability, state of residence, and unobserved idiosyncratic preferences for colleges. Demand for colleges can be modeled using a discrete choice random utility framework. The demand model accounts for the fact that not all students are admitted to selective colleges. Both private and state colleges optimally use minimum ability admission thresholds. Given these admission thresholds, we can determine the set of colleges that are feasible for each student type.

Epple, Romano, Sarpca, and Sieg (2017) also derive the optimal financial aid and pricing policies of private schools, which have a number of interesting properties. First, because private schools set a posted or maximum tuition, a minimum ability threshold that characterizes admission policies of private colleges arises. A certain fraction of students do not obtain financial aid and pay this maximum tuition. These are students that are of relatively low ability in the school and thus do not qualify

\footnotetext{
${ }^{1}$ By net tuition, we mean tuition net of the student's institutional financial aid. We use posted tuition to refer to the amount paid by students that receive no institutional aid.
} 
for merit aid. Moreover, these students must have income sufficiently high so that they are willing to pay the price maximum. Second, net tuition can be expressed as "effective marginal cost" plus a mark-up for all students that are not at the maximum.

Important differences distinguish this model from a standard oligopolistic pricing model. First, effective marginal cost depends on the ability and minority status of a student. Pricing by ability or merit-based aid arises because high ability students increase college quality through reputation and peer effects. Discounts for minority students arise because they enhance diversity. ${ }^{2}$ Second, the mark-up term for a student does not depend on the overall market share of the college, but on the market share conditional on observed student characteristics. We show that these terms can differ by large margins among students, especially for highly selective colleges. Hence "local" or conditional market shares drive mark-ups in the model, and not overall market shares. Third, the mark-up can be decomposed into two additive terms. The first term takes the standard form derived in standard discrete choice demand models. This term reflects idiosyncratic preferences for the school and product differentiation. The second term is monotonically increasing in student or household income capturing pricing by income and arises due to price discrimination. As a consequence, this model is sufficiently rich to generate the qualitative features of tuition policies observed in the U.S. market for higher education.

The first objective of this paper is then to derive a new semi-parametric estimator for the parameters of the model. We can identify and estimate almost all parameters of the model using a method of moments estimator that is based on the difference between the observed and predicted price functions at private colleges. To implement this estimator we need a non-parametric plug-in estimator of the conditional market share for each student at the school that is attended in equilibrium. Our estimation approach does not require us to solve for the equilibrium of the model. ${ }^{3}$ This has the

\footnotetext{
${ }^{2}$ Our paper is, therefore, also related to the recent literature that estimates empirical models of affirmative action. Some recent work includes Hickman (2013), Kapor (2016), and .

${ }^{3}$ The idea of conditioning on observed choice probabilities is similar to Heckman (1979), Hotz and Miller (1993), Berry (1994), and Aguirregabiria and Mira (2002). Our quasi-maximum likelihood
} 
virtue of simplicity. It is also computationally feasible since we do not need to use a nested fixed point algorithm. Moreover, the estimator is consistent for a finite number of elements in the choice set as the number of students in a single cross section goes to infinity.

The second objective of the paper is to implement this estimator using data from the National Postsecondary Student Aid Study. Our sample size consists of approximately 9,500 students that attended a two-year public community college, a four-year public college, or a four-year private college in the U.S. in 2012. Approximately 2,270 students attend a four-year private college. This subsample is the core sample used in estimation. The remaining students that attend public schools are primarily used to estimate the conditional market shares.

While our sample size is large, it is not large enough to estimate a model at the individual college level. ${ }^{4}$ We, therefore, use clustering algorithms to aggregate four-year private colleges into ten types, public four-year colleges into four types, and public two-year colleges into one type. Our empirical demand model thus has 15 different college types. To our knowledge, this is the most disaggregate demand model for higher education that has ever been estimated.

We find that the majority of private colleges engage in pricing by income, ability, and minority status. A $\$ 10,000$ increase in family income increases tuition at private schools by on average $\$ 210$ to $\$ 510$. A one standard deviation increase in ability decreases tuition by approximately $\$ 920$ to $\$ 1,960$ depending on the selectivity of the college. Large and substantial discounts for minority students arise that range between approximately $\$ 110$ (at historically black colleges) and $\$ 5,750$. Average markups in private colleges range between $\$ 750$ and $\$ 13,200$. Much more heterogeneity and some much larger mark-ups occur within colleges than the averages.

estimator is most similar to the one proposed by Bajari, Hong, and Nekipelov (2010) to estimate games with incomplete information.

${ }^{4}$ The NPSAS is the most comprehensive data set available for the U.S., but only samples a subset of all colleges in the U.S. As a consequence some sort of aggregation is unavoidable if one estimates any demand model for higher education using this data set. 
Our paper is related to at least three different areas of research that have focused on markets for higher education. First, there are many empirical papers that have documented that pricing by income, ability and minority status is prevalent in the financial aid data. ${ }^{5}$ Previous structural papers have either ignored this or explained pricing by income by appealing to a motive of serving the poor or providing valued socio-economic diversity on campus. The former approach is taken in most theoretical papers on higher education. The latter approach is taken in Epple, Romano, and Sieg (2006) and Fillmore (2016) who also estimates a model of competitive college pricing. He studies price discrimination and explores restricting colleges' ability to use some or all of the information incorporated in the Free Application for Federal Student Aid (FAFSA). In that case colleges have incentives to use other information that is correlated with FAFSA information.

Second, our work is related to research that has modeled admission and attendance decisions in the market for higher education. The informational environment in our model implies students face no uncertainty in admissions, so we can abstract from an application-admission game with incomplete information. Avery and Levin (2010), Chade, Lewis, and Smith (2014) and Fu (2014) provide a detailed analysis of these issues. Our model also abstracts from choices made by students once they enter college. The most important decision is the choice of a major. Arcidiacono (2005) and Bordon and $\mathrm{Fu}$ (2015) develop and estimate dynamic models of choice of academic major under uncertainty. ${ }^{6}$ Last, in Epple et al. (2017), we have developed the basic theoretical model to examine effects of policy changes on attendance patterns and student costs. We have calibrated the parameters of the model and imposed an equilibrium selection criteria. These simplifications allow us to numerically solve for equilibrium in the model and perform policy analysis. In this paper we extend the model to allow for differences in minority status. Most importantly, we develop and

\footnotetext{
${ }^{5}$ For a discussion of that literature see, among others, Rothschild and White (1995), Hoxby (1997, 1999), Dynarski (2002), Epple, Romano, and Sieg (2003), and McPherson and Schapiro (2006), and Fillmore (2016). van der Klaauw (2002) shows that colleges use price discounts to attract students.

${ }^{6}$ Wiswall and Zafar (2015) exploit an informational experiment to study major choice.
} 
implement a semi-parametric estimator for the parameters of the model. Moreover, we conduct an empirical analysis of price discrimination and market power here.

Finally, our paper is related to recent research on the importance of peer effects in education. Regarding peer effects in schools, there is a large literature by social scientists. Methodological issues are discussed in Manski (1993), Moffitt (2001), and Brock and Durlauf (2001). Recent research on peer effects in higher education includes studies of college dormitory roommates (Sacerdote (2001), Zimmerman (2003), Boisjoly, Duncan, Kremer, Levy, and Eccles (2006), Stinebrickner and Stinebrickner (2006) and Kremer and Levy (2008)), dormitory residential groupings (Foster, 2006), randomly formed groups in military academies (Lyle (2007, 2009) and Carrell, Fullerton, and West (2009)), classroom peer effects (Arcidiacono, Foster, Goodpaster, and Kinsler, 2012), effects of high school peers (Betts and Morell, 1999), and peer effects among medical students (Arcidiacono and Nickolson, 2005). ${ }^{7}$ We do not provide any direct evidence on the importance of peer effects, but provide strong indirect evidence based on our analysis of pricing by ability, income, and minority status.

The rest of the paper is organized as follows. Section 2 introduces our data set and provides descriptive statistics. Section 3 introduces the model that characterizes student sorting among and price and admission policies of colleges. Section 4 introduces a parametrization and discusses our estimator. Section 5 reports our parameter estimates. Section 6 explores the implications of this analysis for mark-ups, market power and price discrimination. Section 7 concludes the analysis.

\section{Data}

Our data source is the 2011-12 National Postsecondary Student Aid Study (NPSAS) from the National Center for Education Statistics (NCES). ${ }^{8}$ Our model focuses on

\footnotetext{
${ }^{7}$ See Epple and Romano (2010) and (Sacerdote, 2011) for a more complete literature survey.

${ }^{8}$ The NPSAS data are accompanied by inverse probability weights that account for the composite probability of sampling, both at the college and individual level. We use these weights throughout the empirical analysis.
} 
initial attendance/matriculation outcomes. We construct our sample using first-year students, who are oversampled in this wave of the NPSAS and constitute more than half of all observations. ${ }^{9}$ We drop some students whose behavior or characteristics require separate modeling. These include multiple attenders-students who switch institutions in their first academic year. ${ }^{10}$ These also include a larger number of students with atypical attendance patterns-those who attend part-time or part-year, as is often the case at two-year colleges. We also drop veterans and athletes because their financial aid opportunities are different from those faced by the average student, and their priorities in selecting an institution may also differ. We drop foreign students (or students with no state residence) for two reasons: (i) Their choice sets possibly include the universities in their home country, as well as universities in other nonhome countries (based on their decision to study abroad); and (ii) their eligibility for financial aid and their pricing by colleges may differ.

Ability is a key variable in our analysis, and we drop observations with missing components of the ability measures (ACT or SAT score and high school GPA). ${ }^{11}$ We drop all students attending schools at which we cannot match institutional expenditures. Finally there are a few sample schools that offer both 4-year and 2-year degrees, and we drop their 2-year enrollees (the minority) and treat them as 4-year institutions. The resulting sample consists of approximately 9,490 students. Table 1 presents the numbers of these groups of students along with their distribution over different types of colleges.

Table 2 presents selected statistics from our sample. Our measure of ability is

\footnotetext{
${ }^{9}$ College completion and continuation decisions are likely to differ from the initial matriculation decision. Also, family resources and aid packages in later years of attendance need not be identical to those in the student's first year. For these reasons we use first-year students in our analysis.

${ }^{10}$ These constitute about 4 percent of the sample, dropped because we cannot know if the switch was planned from the point of matriculation, and so the decision space would become much more complex.

${ }^{11}$ As approximately $40 \%$ of first-year public 2-year students do not take SATs or ACTs, it is possible that the remaining sample is of higher ability than the general student body. Thus, our measure of average peer quality may be biased upward for this college, and we will underestimate the quality differentiation among the lowest-tier colleges. However, there is no other viable measure of student ability, and so this is an unavoidable challenge to estimation.
} 
Table 1: Sample Selection

\begin{tabular}{l|ccc|c}
\hline & 2-year public & 4-year public & 4-year private & Total \\
\hline Full NPSAS 2012 & 31,000 & 17,300 & 9,010 & 57,300 \\
First-year only & 17,860 & 4,530 & 4,210 & 26,590 \\
No atypical attendance & 5,380 & 3,370 & 3,470 & 12,220 \\
No athletes & 5,330 & 3,310 & 3,280 & 11,910 \\
No veterans & 5,190 & 3,230 & 3,230 & 11,660 \\
No missing ability & 4,180 & 3,160 & 3,170 & 10,510 \\
No missing state & 4,150 & 3,130 & 3,090 & 10,370 \\
No missing school expenditures & 3,510 & 2,910 & 3,070 & 9,490 \\
\hline
\end{tabular}

Note: Unweighted counts rounded to nearest 10 as per NCES policy.

predicted college GPA-we model college GPA as a function of high school GPA, ACT or SAT score, gender, major, and college fixed effects in a sample of non-minority four-year college students. We then predict GPA at a generic college, using only the recovered parameters for high school GPA, ACT/SAT score, and gender. ${ }^{12}$ This ability measure is then transformed to have unit standard deviation and positive mean. The choice of mean ensures that the average ability at each college is weakly greater than zero. ${ }^{13}$

Our measure of income is adjusted gross income in 2010. Where possible, NPSAS computes this value based on the federal financial aid application, and uses total income (of family or student as implied by dependency status) reported in the student interview where no application or tax return are available. The 2010 value is used as federal financial aid eligibility for 2011-2012 school year would be based on 2010 income. Race, ethnicity, and gender are drawn from the student interview where possible, and from student records when no interview is possible.

In-state status is determined by comparing the student's reported state of residence

\footnotetext{
${ }^{12} \mathrm{We}$ do not account for minority status in this regression although it could be easily done. A priori one can make arguments in favor and against either approach.

${ }^{13}$ Appendix A provides additional details. It also explains the construction of the ability thresholds used for each cluster.
} 
with the imputed availability of public college types. We calculate total institutional aid by taking the sum of institutional grants, one-half of work study, and one-quarter of loans. Thus, net tuition is the posted tuition less the sum of institutional aid (federal aid is considered separately).

Table 2: Selected Characteristics for NPSAS 2012 Sample

\begin{tabular}{l|ccc|c}
\hline & Public 2-yr & Public 4-yr & Private 4-yr & All \\
\hline Number of students & 3,510 & 2,910 & 3,070 & 9,490 \\
Number of students (weighted)* & 521,638 & 583,844 & 342,519 & $1,448,001$ \\
Number of Colleges & 300 & 250 & 350 & 900 \\
Number of Colleges (weighted)** & 1549 & 713 & 1286 & 3548 \\
Average ACT Score & 19.72 & 21.88 & 23.79 & 21.55 \\
Average Ability & 0.00 & 0.45 & 0.81 & 0.37 \\
Average In-state Net Tuition*** & 3.00 & 5.73 & 26.37 & 12.02 \\
Average Out-of-state Net Tuition & 6.48 & 15.48 & 26.37 & 15.50 \\
Average Income & 48.4 & 76.9 & 94.8 & 70.9 \\
Female & 0.53 & 0.54 & 0.57 & 0.55 \\
Black & 0.18 & 0.17 & 0.14 & 0.17 \\
Hispanic & 0.19 & 0.13 & 0.11 & 0.15 \\
\hline
\end{tabular}

*Students are weighted to be nationally representative, using inverse probability weights provided by the NCES. All other student-level statistics (e.g. ACT score, gender) are also weighted.

**Colleges are weighted to be nationally representative, using inverse probability weights provided by the NCES. Tuition values are also weighted.

$* * *$ Tuition and income reported in $\$ 1,000$ s.

Note: Unweighted counts rounded to nearest 10 as per NCES policy.

Federal aid is limited to Pell grants, which are calculated by the formula

$$
A=\min \{\max \{0, C O A-E F C(y)\}, 5500\}
$$

where $C O A$ is the federally determined cost-of-attendance and $E F C(y)$ the federally determined expected family contribution, which increases with household income. Pell grants are awarded up to $C O A-E F C$ if positive, but with a maximum of 
\$5500. However, in practice, we use the amended formula:

$$
A=\min \left\{\max \left\{0, \overline{p_{j}}+L-E F C(y)\right\}, 5500\right\},
$$

as cost of attendance - posted tuition $\left(\bar{p}_{j}\right)$ plus estimated non-tuition costs $(L)$ - varies by student-college combination and is only occasionally observed at the attended college, and never observed for potential alternatives. EFC is directly reported in the NPSAS, and thus can be used both for the attended college as well as the potential alternatives.

Then we calculate the Pell aid at each college using the above formula, also adjusting to account for the Pell minimum award (in 2012, 555 dollars). Any student offered at least half of the minimum, but less than the minimum, is given the minimum, and any student eligible for less than half of the minimum was awarded no aid. Additionally, we have many "never-takers" in our sample, and so if we observe a student to be a non-taker at the attended college when eligible for some aid, we assume the student is a never-taker at all colleges.

Our sample includes observations from approximately 900 colleges. The number of students observed per college averages about 11. Having more observations per college is desirable for precision when testing within-college predictions of the model. At the same time, our model implies that colleges with similar characteristics would make similar admission and pricing decisions. Working with smaller choice sets (fewer colleges) also has computational advantages. For these reasons, we group together colleges that are similar in their key characteristics, treating them as one college. We group public and private colleges separately based on the joint variance of posted tuition, average ACT score, and instructional expenditures per student, using $k$-means clustering. We choose the number of clusters based on the elbow method, increasing the number of clusters until the marginal cluster does not significantly decrease the within-group variance, which suggests approximately four clusters of public four-year colleges, and approximately twelve clusters of private four-year colleges. 


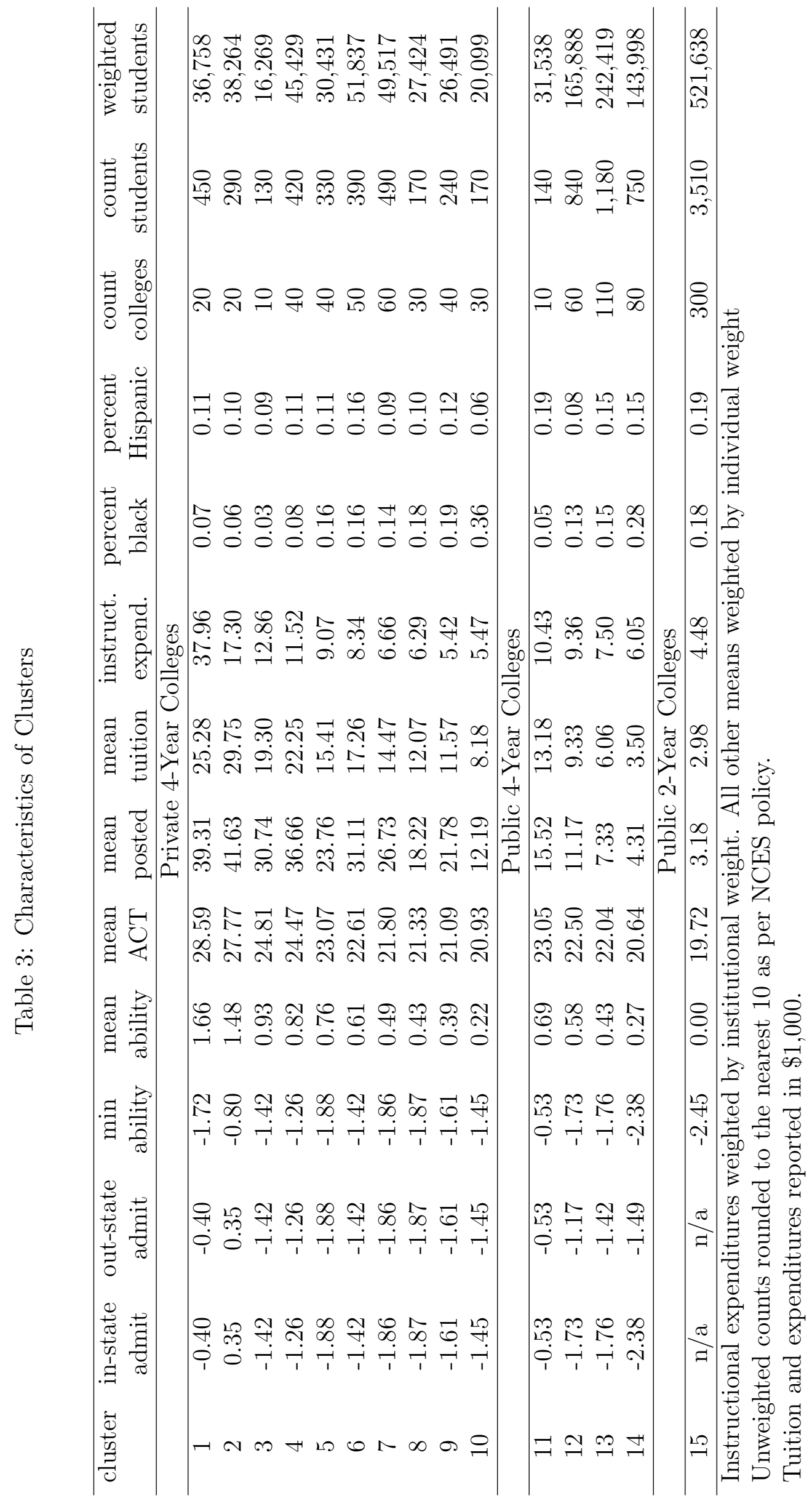


The "rule of thumb" relates the suggested $k$ to the number of schools to cluster, $k=\sqrt{\frac{n}{2}}$, implies approximately 13 private clusters $\left(n_{\text {priv }}=350\right)$. We initially create twelve private clusters, but then combine two sets of resulting cluster pairs to ensure an adequate sample size of students at each cluster. Table 3 presents the key characteristics of private and public clusters, ordered within the two college groups by mean ACT. The term "college" will refer to a cluster in the rest of the paper. ${ }^{14}$

\section{A Model of Price Discrimination}

In this section, we briefly review the model derived in Epple, Romano, Sarpca, and Sieg (2017) and derive the key implications for optimal admission and pricing policies. The main difference between the model that we estimate in this paper and the model that was used in Epple, Romano, Sarpca, and Sieg (2017) is that we add minority status as a student characteristic and thus study the pricing implications of preferences for diversity.

We consider a model with $S$ regions or states and normalize the student population in the economy to 1 . Let $\pi_{s}$ denote the student population proportions or size of each state and note that $\sum_{s=1}^{S} \pi_{s}=1$. Students in each state differ continuously by aftertax income $y$ and ability $b$. Students also differ by minority status which is a discrete indicator variable $m \in\{0,1\}$. Let $f_{s}(b, y \mid m)$ denote the density of $(b, y)$ in state $s$ conditional on $m$. The fraction of of type $m$ households in state $s$ is denoted by $\pi_{s m}$; note that $\sum_{m} \pi_{s m}=\pi_{s}$.

For expositional simplicity, we assume each state operates one public university. In our application discussed below, we extend the model and allow for product differentiation among public colleges within a state. ${ }^{15}$ In addition to the $S$ public universities,

\footnotetext{
${ }^{14}$ Treating clusters as one college assumes: (i) students perceive colleges within a cluster as equivalent; and (ii) either students apply to no more than one college within a cluster or that colleges within clusters effectively collude. Since we have 14 clusters and students that qualify for a cluster can attend at their price, we are not significantly limiting the choice set of students.

${ }^{15}$ Our empirical model allows for up to four public types in each state.
} 
there are $P$ private universities that operate nationwide and also compete for students. There is an outside option which we model as attending a two-year public college. The total number of alternatives is then $J=S+P+1$. $^{16}$

A student with ability $b$ that attends a university of quality $q_{j}$ has an achievement denoted by $a\left(q_{j}, b\right)$. Let $p_{s j}(m, b, y)$ denote the tuition that a student from state $s$ with ability $b$, income $y$, and minority status $m$ pays for attending college $j$. Let $A_{s j}(y)$ denote federal aid and $L$ the non-tuition cost of attending a college. Federal aid depends on income and the cost of attending a college, which varies with a student's state of residence if attending a state college. Let $\varepsilon_{j}$ denote an idiosyncratic preference shock for college $j$, which is private information of the student.

The utility of student $(s, m, b, y)$ for college $j$ is additively separable in the idiosyncratic component and given by:

$$
U_{j}\left(s, m, b, y, \varepsilon_{j}\right)=U\left(y-p_{s j}(m, b, y)-L+A_{s j}(y), a\left(q_{j}, b\right)\right)+\varepsilon_{j} .
$$

$U(\cdot)$ is an increasing, twice differentiable, and quasi-concave function of the numeraire and educational achievement, $\mathrm{a}(\cdot)$. Educational achievement is an increasing, twice differentiable, and strictly quasi-concave function of college quality and own ability.

Utility depends on location and minority status because tuition depends on location and minority status. The dependence on location can arise for two reasons. First, state colleges are likely to give preferential treatment to in-state students. Second, private colleges may use different mark-ups to students coming from different states because these students may face different state college options. The dependence on minority status follows from the fact that colleges value diversity as discussed below.

Let $S_{a}(s, m, b)$ denote the subset of state colleges to which student $(s, m, b, y)$ is admitted, $P_{a}(s, m, b)$ the same for private colleges, and $J_{a}(s, m, b) \subset S_{a}(s, m, b) \cup$

\footnotetext{
${ }^{16}$ We abuse notation for convenience by using $S$ to denote both the number of state colleges and the set of them $\{1,2, \ldots, S\}$, and likewise for $P$ and $J$ (which usage will be obvious by context). Also for expositional convenience, we sometimes refer to university $j$ from the set of all alternatives $J$, though this includes non-universities like the two-year public college.
} 
$P_{a}(s, m, b) \cup O$ the options that provide positive utility available to the student. ${ }^{17}$ Taking as given tuitions, qualities, and non-institutional aid, student $(s, m, b, y)$ chooses among $j \in J_{a}(s, m, b)$ to maximize utility (1). Let the optimal decision rule be denoted by $\delta(s, m, b, y, \varepsilon)$. The vector $\varepsilon$ satisfies standard regularity assumptions in McFadden (1974).

Integrating out the idiosyncratic taste components yields conditional choice probabilities for each type:

$$
r_{s j}(m, b, y ; P(m, s, b, y), Q)=\int 1\left\{\delta_{j}(s, m, b, y, \varepsilon)=1\right\} g(\varepsilon) d \varepsilon
$$

where $1\{\cdot\}$ is an indicator function, $\delta_{j}(\cdot)=1$ means college $j$ is chosen, $P(s, m, b, y)$ denotes the vector of tuitions that apply to student type $(s, m, b, y)$, and $Q$ denotes the vector of college qualities.

Private colleges attract students from all states of the country. Their objective is to maximize quality. College $j$ has a cost function

$$
C_{j}\left(k_{j}, I_{j}\right)=F_{j}+V_{j}\left(k_{j}\right)+k_{j} I_{j}
$$

where $k_{j}$ denotes the size of college $j$ 's student body and $I_{j}$ expenditures per student on educational resources in college $j$. The costs $F_{j}+V_{j}\left(k_{j}\right)$ are independent of educational quality, which we refer to as "custodial costs." Moreover, each college obtains an exogenous amount of non-tuition income denoted by $E_{j}$, e.g., from endowment earnings Finally, private colleges also have exogenous posted or maximum tuitions, denoted by $\bar{p}_{j}{ }^{18}$

Letting $\theta_{j}$ denote mean ability in college $\mathrm{j}$ 's student body and $\Gamma_{j}$ the fraction of

\footnotetext{
${ }^{17}$ Admission is independent of income, though net tuition will vary with income.

${ }^{18}$ In reality, private colleges have a posted (advertised) tuition, which is what almost every student among those that do not receive any institutional aid pay. Setting a maximum tuition, rather than having tuition strictly monotonic in income (for given other student attributes), is likely explained by a combination of social/political marketing and uninformed students who are unaware of financial aid. For tractability, we do not model the latter elements, and we then treat a private college's posted tuition as given in the theory.
} 
minority students, college quality is given by

$$
q_{j}=q_{j}\left(\theta_{j}, I_{j}, \Gamma_{j}\right)
$$

which is a twice differentiable, increasing, and strictly quasi-concave function of $\left(\theta_{j}, I_{j}, \Gamma_{j}\right)$. Quality increases with average student ability due to a combination of peer learning effects, non-learning externalities from developing relationships with high ability peers, and reputation effects. ${ }^{19}$ Quality increases with diversity as having diverse student peers enhances post-college success in a diverse workplace. ${ }^{20}$

Colleges maximize quality behaving as monopolistic competitors. Private college $j$ takes as given other colleges' tuitions and qualities when maximizing quality. We can write the quality optimization problem of private college $j$ as follows:

$$
\max _{\theta_{j}, I_{j}, \Gamma_{j}, k_{j}, p_{s j}(m, b, y)} q\left(\theta_{j}, I_{j}, \Gamma_{j}\right)
$$

subject to a revenue constraint

$$
R_{j}=\iint \sum_{s=1}^{S} \sum_{m} \pi_{s m} p_{s j}(m, b, y) r_{s j}(m, b, y ; P(m, s, b, y), Q) f_{s}(b, y \mid m) d b d y+E_{j}
$$

a budget constraint

$$
R_{j}=F_{j}+V_{j}\left(k_{j}\right)+k_{j} I_{j}
$$

identity constraints,

$$
\theta_{j}=\frac{1}{k_{j}} \iint b\left(\sum_{s=1}^{S} \sum_{m} \pi_{s m} r_{s j}(m, b, y ; P(m, s, b, y), Q) f_{s}(b, y \mid m)\right) d b d y
$$

\footnotetext{
${ }^{19}$ In as much as there are non-learning and reputation effects of having higher ability peers embodied in $\theta$, what we have labeled "achievement" must be more broadly interpreted as any utility enhancing college effect. See, for example, MacLeod and Urquiola (2015).

${ }^{20}$ Our assumption that quality increases with the proportion of minorities assumes they are underrepresented.
} 


$$
\begin{gathered}
k_{j}=\iint\left(\sum_{s=1}^{S} \sum_{m} \pi_{s m} r_{s j}(m, b, y ; P(m, s, b, y), Q) f_{s}(b, y \mid m)\right) d b d y, \\
\Gamma_{j}=\iint\left(\sum_{s=1}^{S} \pi_{s 1} r_{s j}(1, b, y ; P(1, s, b, y), Q) f_{s}(b, y \mid 1)\right) d b d y / k_{j}
\end{gathered}
$$

and the maximum price constraint

$$
p_{s j}(m, b, y) \leq \bar{p}_{j}
$$

We can solve the private college's problem. ${ }^{21}$ Assuming that (11) is not binding, for any student $(s, m, b, y)$ with $r_{s j}>0$, tuition satisfies:

$$
p_{s j}(m, b, y)+\frac{r_{s j}(m, b, y ; \cdot)}{\partial r_{s j}(m, b, y ; \cdot) / \partial p_{s j}(m, b, y)}=E M C_{j}(m, b)
$$

where

$$
E M C_{j}(m, b) \equiv V_{j}^{\prime}+I_{j}+\frac{q_{\theta}}{q_{I}}\left(\theta_{j}-b\right)+\frac{q_{\Gamma}}{q_{I}}\left(\Gamma_{j}-m\right)
$$

The left-hand side of (12) is the usual expression for marginal revenue. The righthand side of expression (12) is the "effective marginal cost" of student $(s, m, b, y)$ 's attendance, which sums the marginal resource cost given by the first two terms and the marginal peer costs given by the last two terms. The ability-based marginal peer cost (third term) multiplies the negative of the student's effect on the peer measure (equal to $(\theta-b) / k$ ) by the resource cost of maintaining quality (equal to $\frac{\partial q / \partial \theta}{\partial q / \partial I} k$ ). The diversity marginal peer cost has analogous decomposition. Note that $E M C$ varies with students in college $j$ only with the student's ability and minority status. The ability-based marginal peer cost is negative for students of ability exceeding the college's mean, and the diversity-based marginal peer cost is negative for minorities.

\footnotetext{
${ }^{21} \mathrm{An}$ appendix is available upon request from the authors that derives the optimality conditions for the private and the public school's optimization problem.
} 
Students $(m, b, y)$ are admitted to the college if and only if

$$
\min \left\{\bar{p}_{j}, p_{s j}(m, b, y)\right\} \geq E M C_{j}(m, b)
$$

Equation (14) yields minimum ability thresholds that vary with minority status for each private college implicitly defined by:

$$
\bar{p}_{j}=E M C_{j}\left(m, b_{j m}^{\min }\right)
$$

Since effective marginal cost decreases with ability and is lower for a minority student of given ability, the admission threshold for minorities is lower.

It is interesting to compare the tuition results to that for a profit-maximizing private college. It is not hard to show that a profit-maximizing college would have a tuition function that is of the exact form of (12). The main objective of the paper is to determine the empirical content of the pricing equation in (12). Our estimation approach, discussed in detail in the next section, is therefore consistent with quality or profit maximization assumptions.

Distinguishing quality and profit maximization empirically would require distinguishing relatively subtle differences between equilibria under the two alternatives. ${ }^{22}$ Given educational inputs, the quality maximizing college sets tuition to maximize profits, while taking account of the peer value effects, so as to have the maximum funds to increase quality. However, the quality maximizing college has stronger incentive to spend on educational inputs, implying inputs will be higher in (12). Moreover, if the quality function is such that $q_{\theta} / q_{I}$ increases with $I$, as we might expect, then the weight on the ability-based peer effect $(\theta-b)$ in (13) will differ, implying the quality maximizer has stronger incentives to attract higher ability students. Likewise, the quality maximizer has stronger incentives to attract minorities.

\footnotetext{
${ }^{22}$ See Epple and Romano $(1998,2008)$ for an analysis of profit maximization by (secondary) schools in a related model.
} 
To test the implications of equation (12), we need to close the demand model and derive the conditional market shares for each private college. For that we need to derive the admission policies of state schools. From an empirical perspective, we will only require that public colleges adopt minimum ability admission thresholds that depend on the state of residence and the minority status of the student. Next we summarize a model of state colleges that generates admission policies that have these properties.

From the perspective of a state college, a student with characteristics $(m, b, y)$ is either an in-state student or an out-of-state student. We assume that tuition charged to in-state students is fixed exogenously at $T_{s}$ and to out-of-state students at $T_{\text {so }}$. Epple, Romano, Sarpca, and Sieg (2017) then show that state schools that maximize aggregate achievement of their in-state students use ability threshold rules to determine access to the school. These thresholds differ for in-state and out-of state students. ${ }^{23}$ With these results in hand, we are now in a position to turn to empirical analysis and determine whether the predictions of this model regarding pricing and demand are consistent with the observed data.

\section{Estimation}

\subsection{A Parametrization}

To estimate the model we need to invoke some additional parametric assumptions.

\section{Assumption 1}

\footnotetext{
${ }^{23}$ With $T_{s o}>T_{s}$, as hold empirically, the ability threshold for admitting in-state versus out-ofstate students can be higher or lower theoretically. Out-of-state are valued by state schools for their peer spillovers and higher regulated tuition. This can lead their admission threshold to be higher or lower depending on the relative weight in the quality function on the peer effect to the resource effect. Note, too, these admission thresholds will each be lower for minority status, though this was not analyzed in Epple, Romano, Sarpca, and Sieg (2017).
} 
a) The quality function is given by

$$
q_{j}=\theta_{j}^{\gamma} I_{j}^{\omega} \Gamma_{j}^{\kappa} e^{u_{j}}, \gamma, \omega, \kappa>0
$$

where $u_{j}$ is an unobserved exogenous characteristic.

b) The utility function is given by:

$$
U_{j}\left(y-p_{s j}-L+A_{s j}, a\left(q_{j}, b\right)\right)=\alpha \ln \left(y-p_{s j}-L+A_{s j}\right)+\alpha \ln \left(q_{j} b^{\beta}\right)+\epsilon_{j}, \beta, \alpha>0
$$

where $\alpha$ parameterizes the weight on the systematic component of utility.

c) The disturbances $\varepsilon_{j}$ are independent and identically distributed with Type I Extreme Value Distribution.

The assumptions above then imply that the conditional choice probability for type $(s, m, b, y)$ is given by, for $\mathrm{j} \in J_{a}(m, s, b)$ :

$$
r_{s j}(m, b, y)=\frac{\left[\left(y-p_{s j}(m, b, y)-L+A_{s j}(y)\right) q_{j}\right]^{\alpha}}{\sum_{k \in J_{a}(m, s, b)}\left[\left(y-p_{s k}(m, b, y)-L+A_{s k}(y)\right) q_{k}\right]^{\alpha}} .
$$

The pricing equation (12) for private colleges can then be written:

$$
p_{s j}(m, b, y)=\frac{\left(1-r_{s j}\right) \alpha}{1+\left(1-r_{s j}\right) \alpha} E M C_{j}(m, b)+\frac{1}{1+\left(1-r_{j s}\right) \alpha}\left(y-L+A_{s j}(y)\right)
$$

Effective marginal costs at private colleges are given by:

$$
E M C_{j}(m, b)=V_{j}^{\prime}+I_{j}+\frac{\gamma I_{j}}{\omega \theta_{j}}\left(\theta_{j}-b\right)+\frac{\kappa I_{j}}{\omega \Gamma_{j}}\left(\Gamma_{j}^{m}-m\right)
$$

The pricing function is then:

$$
\begin{aligned}
p_{s j}(m, b, y) & =\frac{\left(1-r_{s j}\right) \alpha}{1+\left(1-r_{s j}\right) \alpha}\left(V_{j}^{\prime}+I_{j}+\frac{\gamma I_{j}}{\omega \theta_{j}}\left(\theta_{j}-b\right)+\frac{\kappa I_{j}}{\omega \Gamma_{j}}\left(\Gamma_{j}-m\right)\right) \\
& +\frac{1}{1+\left(1-r_{j s}\right) \alpha}\left(y-L+A_{s j}(y)\right)
\end{aligned}
$$


In addition we simplify notation by writing the marginal resource costs as

$$
V_{j}=V^{\prime}\left(k_{j}\right)+I_{j}
$$

We treat the $V_{1}, \ldots V_{J}$ as additional parameters to be estimated.

The model implies an appealing decomposition of tuition. From (19), observe that tuition to student $(s, m, b, y)$ is a convex combination of the student's effective marginal cost and cost adjusted income. The linkage of tuition to ability and minority status reflects the student's within college externality, which is independent of market power. The linkage to income reflects market power over the student type $(s, m, b, y)$. The weight on income increases with the student type's market share at the college indicating increased market power over the student. The weight on income decreases with $\alpha$, the weight on the systematic component of utility. This indicates that market power declines as idiosyncratic preferences become less important.

\subsection{The Information Set}

The information set of the econometrician can be characterized as follows.

\section{Assumption 2}

- We observe a sample $i=1, \ldots, N$. Let $s_{i}$ denote the state of student $i, m_{i}$ the minority status, $b_{i}$ ability, $y_{i}$ income and $p_{s j i}$, the tuition at college $j$. Note that we only observe the tuition at the college attended in equilibrium. Let $d_{j i}$ denote an indicator which is equal to one if student $i$ attends college $j$ and zero otherwise.

- L is known.

- $\theta_{j}, I_{j}, k_{j}$ are known for all $j$.

- In- and out-of-state tuitions at state colleges $\left(\bar{p}_{j s}\right)$ and posted prices at private colleges $\left(\bar{p}_{j}\right)$ are known. 
- $A_{\text {sij }}\left(y_{i}\right)$ are observed for all $i$ and $j$.

- Prices for all students $i$ at private colleges that are not paying the posted price are measured with classical error:

$$
\tilde{p}_{s j i}=p_{s i j}\left(m_{i}, b_{i}, y_{i}\right)+v_{i j}
$$

where $v_{i j}$ is iid across $i$ and $j$.

\subsection{A Semi-parametric Estimator}

Consider the subsample of students that attend private colleges and are not paying the full posted price, i.e. the subsample of students at private schools that obtain some institutional aid. Using this subsample we can identify and estimate most of the parameters of the model using the predictions of the model about price discrimination. In particular, we can implement the following semi-parametric estimator.

We non-parametrically estimate the conditional market shares $r_{s j}(m, b, y)$ for all students for the private college that is attended in the data. We use a simple flexible Logit estimator using a quadratic approximation in $b$ and $y$, where the coefficients depend on $m$ and $s$. We then use the estimated Logit model to predict the conditional choice probability denoted by $\hat{r}_{s j}(m, b, y)$. Alternatively, we could use nonparametric techniques such as kernel or sieve estimators.

Substituting the estimator of the conditional market share into the pricing equation, we obtain:

$$
\begin{aligned}
\tilde{p}_{s j i} & =\frac{\left(1-\hat{r}_{s j}\right) \alpha}{1+\left(1-\hat{r}_{s j}\right) \alpha}\left(V_{j}+I_{j}+\frac{\gamma I_{j}}{\omega \theta_{j}}\left(\theta_{j}-b\right)+\frac{\kappa I_{j}}{\omega \Gamma_{j}}\left(\Gamma_{j}-m\right)\right) \\
& +\frac{1}{1+\left(1-\hat{r}_{j s}\right) \alpha}\left(y-L+A_{s j}(y)\right)+v_{j i}
\end{aligned}
$$

where $v_{j i}$ is the measurement error term. We can, therefore, identify and estimate $\alpha$, the ratios $\gamma / \omega$ and $\kappa / \omega$, as well as the marginal costs $V_{1}, \ldots, V_{J}$ using a semi-parametric 
NLLS estimator based on equation (24). We use a bootstrap algorithm to estimate the standard errors to account for the sequential nature of the estimation procedure.

All the empirical results reported on this paper are based on this estimator. One nice property of this estimator is that it is consistent for large $N$, but small $J$. This scenario is relevant for most practical applications.

For certain applications, knowledge of the level of $\omega, \gamma$, and $\kappa$ is useful. Appendix B of this paper discusses how to identify and estimate the levels of these parameters using a semi-parametric estimator that extends the estimators suggested Berry (1994) and Berry, Levinsohn, and Pakes (1995).

\section{$5 \quad$ Parameter Estimates}

Table 4 summarizes the parameter estimates for our model. Note that these estimates are based on the subsample of students at private universities that received a positive amount of institutional financial aid. The relevant sample size is 2,270. Note that we only need the other students to construct the correct measures of the conditional market shares which then enter into the pricing equation. We estimate three types of model specifications. The first two specifications ignore minority status while the

third specification - which is our preferred specification - also accounts for minority status. Dollar amounts are measured in tens of thousands.

The first column uses unweighted data. The second and third column uses the weights suggested by NPSAS. Comparing the weighted estimates in Column 2 with the unweighted estimates in Column 1, we find only small differences in the estimated parameter values. The main difference is that the unweighted estimator yields a somewhat greater point estimate of $\alpha$. The estimates in Column 2 are similar to the ones in Column 3.

Focusing on our preferred estimates in Column 3 we obtain an estimate of $\alpha$ which is equal to 72.72 with an estimated standard error of 7.13. As a consequence we find 
that our estimate is highly significant at standard levels of significance. Note that $\alpha$ is primarily identified from the observed pricing by income.

Table 4: Parameter Estimates

\begin{tabular}{|c|c|c|c|}
\hline & $(1)$ & $(2)$ & $(3)$ \\
\hline Weights & No & Yes & Yes \\
\hline Minority Status & No & No & Yes \\
\hline$\alpha$ & $\begin{array}{l}86.56^{* * *} \\
(8.58)\end{array}$ & $\begin{array}{l}70.26^{* * *} \\
(6.68)\end{array}$ & $\begin{array}{l}72.72^{\text {*** }} \\
(7.13)\end{array}$ \\
\hline$\frac{\gamma}{\omega}$ & $\begin{array}{l}0.074^{* * *} \\
(0.012)\end{array}$ & $\begin{array}{l}0.0734^{* * *} \\
(0.012)\end{array}$ & $\begin{array}{l}0.079^{* * *} \\
(0.012)\end{array}$ \\
\hline$\frac{\kappa}{\omega}$ & & & $\begin{array}{l}0.01^{* * *} \\
(0.003)\end{array}$ \\
\hline$V_{1}$ & $\begin{array}{l}1.22^{* * *} \\
(0.07)\end{array}$ & $\begin{array}{l}1.21^{* * *} \\
(0.07)\end{array}$ & $\begin{array}{l}1.23^{* * *} \\
(0.07)\end{array}$ \\
\hline$V_{2}$ & $\begin{array}{l}1.69 * * * \\
(0.07)\end{array}$ & $\begin{array}{l}1.65^{* * *} \\
(0.07)\end{array}$ & $\begin{array}{l}1.66^{* * *} \\
(0.07)\end{array}$ \\
\hline$V_{3}$ & $\begin{array}{l}1.43^{* * *} \\
(0.08)\end{array}$ & $\begin{array}{l}1.40^{* * *} \\
(0.08)\end{array}$ & $\begin{array}{l}1.41^{* * *} \\
(0.08)\end{array}$ \\
\hline$V_{4}$ & $\begin{array}{l}1.82^{* * *} \\
(0.05)\end{array}$ & $\begin{array}{l}1.81^{* * *} \\
(0.05)\end{array}$ & $\begin{array}{l}1.82^{* * *} \\
(0.05)\end{array}$ \\
\hline$V_{5}$ & $\begin{array}{l}1.15^{* * *} \\
(0.05)\end{array}$ & $\begin{array}{l}1.14^{* * *} \\
(0.05)\end{array}$ & $\begin{array}{l}1.14^{* * *} \\
(0.05)\end{array}$ \\
\hline$V_{6}$ & $\begin{array}{l}1.48^{* * *} \\
(0.04)\end{array}$ & $\begin{array}{l}1.46^{* * * *} \\
(0.04)\end{array}$ & $\begin{array}{l}1.46^{* * *} \\
(0.04)\end{array}$ \\
\hline$V_{7}$ & $\begin{array}{l}1.15^{* * *} \\
(0.04)\end{array}$ & $\begin{array}{l}1.13^{* * *} \\
(0.04)\end{array}$ & $\begin{array}{l}1.14^{* * *} \\
(0.04)\end{array}$ \\
\hline$V_{8}$ & $\begin{array}{l}0.93 * * * \\
(0.07)\end{array}$ & $\begin{array}{l}0.92^{* * *} \\
(0.07)\end{array}$ & $\begin{array}{l}0.92^{* * *} \\
(0.07)\end{array}$ \\
\hline$V_{9}$ & $\begin{array}{l}1.09 * * * \\
(0.05)\end{array}$ & $\begin{array}{l}1.08^{* * *} \\
(0.05)\end{array}$ & $\begin{array}{l}1.08^{* * *} \\
(0.05)\end{array}$ \\
\hline$V_{10}$ & $\begin{array}{l}0.56^{* * *} \\
(0.08)\end{array}$ & $\begin{array}{l}0.54^{* * *} \\
(0.08)\end{array}$ & $\begin{array}{l}0.54^{* * *} \\
(0.08)\end{array}$ \\
\hline
\end{tabular}

Next consider the ratio of $\frac{\gamma}{\omega}$. Our point estimate equals 0.079 with an estimated standard error of 0.012 . This ratio is primarily identified off the observed merit based aid. We conclude that both key parameters are estimated with high precision. The quantitative implications of these estimates are discussed below. 
Our point estimate for the ratio of $\frac{\kappa}{\omega}$ is 0.012 with a standard error of 0.003 . This ratio is primarily identified off the observed institutional aid to minority students holding income and ability fixed. The average predicted marginal effect of being a minority student in our model is a $\$ 900$ discount. We conclude that our model provides strong evidence that private schools care about racial diversity.

We can also estimate the marginal resource costs of admitting an additional student to the college. Not surprisingly, we find that there is much heterogeneity in marginal costs. Our estimates range between approximately $\$ 5,400$ and $\$ 16,600$. Note that these estimates combine marginal expenditures on educational inputs and marginal custodial costs.

We conclude that our estimator performs well and provides reasonable estimates for the key parameters. Next we explore the implications of our model estimates for price discrimination and market power in the market of higher education.

\section{Price Discrimination in U.S. Higher Education}

Table 5 reports the average derivatives of price in ability and in income implied by our model and compares these predictions to simple reduced form OLS estimates with fixed cluster effects. It is instructive to compare these estimates, which embody the structural properties of our model, to OLS estimates that simply assume linear pricing. Overall, we find that our model captures well the basic regularities in the data revealed by OLS. Of course, the payoff from our model is that we can assess the role of local market power and nonlinearities in the patterns of pricing by income and ability that are observed in the data.

To gain some additional insights into the predicted magnitude of pricing by income and ability as well as the extent of market power, it useful to decompose the prices paid by students into the different components. For students not paying the posted 
Table 5: Pricing by Ability and Income

\begin{tabular}{|c|c|c|c|}
\hline & (1) & $(2)$ & (3) \\
\hline Weights & No & Yes & Yes \\
\hline Minority Status & No & No & Yes \\
\hline \multicolumn{4}{|c|}{ Structural Estimates of Pricing by Ability and Income } \\
\hline$\frac{\partial p}{\partial b}$ & $-0.095^{* * *}$ & $-0.105^{* * *}$ & $-0.112^{* * *}$ \\
\hline$\frac{\partial p}{\partial y}$ & $0.013^{* * *}$ & $0.015^{* * *}$ & $0.014^{* * *}$ \\
\hline \multicolumn{4}{|c|}{ Reduced Form Estimates of Pricing by Ability and Income } \\
\hline$\frac{\partial p}{\partial b}$ & $-0.113^{* * *}$ & $-0.112^{* * *}$ & $-0.121^{* * *}$ \\
\hline$\frac{\partial p}{\partial y}$ & $0.017^{* * *}$ & $0.016^{* * *}$ & $0.016^{* * *}$ \\
\hline \multicolumn{4}{|c|}{ Note $^{*} \mathrm{p}<0.1 ;{ }^{* *} \mathrm{p}<0.05 ;{ }^{* * *} \mathrm{p}<0}$. \\
\hline
\end{tabular}

price, the marginal effect of ability on price is approximately given by:

$$
\frac{\partial p_{s j}(m, b, y)}{\partial b} \approx-\frac{\left(1-r_{s j}\right) \alpha}{1+\left(1-r_{s j}\right) \alpha} \frac{\gamma I_{j}}{\omega \theta_{j}}
$$

The marginal effect of income on price is approximately:

$$
\frac{\partial p_{s j}(m, b, y)}{\partial y} \approx \frac{1}{1+\left(1-r_{j s}\right) \alpha}
$$

We compute the "mark-up" as the difference between price and effective marginal cost:

$$
\operatorname{mark-up}_{j}(s, m, b, y)=p_{s j}(m, b, y)-E M C_{j}(m, b) .
$$

Computing the mark-up over $E M C$, rather than the more standard mark-up over marginal resource cost, is to capture market power by purging the discounts to ability and minority status that reflect externalities.

Table 6 shows the value of the average mark-up and the marginal pricing by ability and income terms for each cluster (i.e., each column). Average mark-ups rise rapidly along the quality hierarchy, ranging above $\$ 13,000$ for elite colleges. Our estimates imply little difference in average pricing by income. The average effects range between 
Table 6: Predicted Mark-ups and Pricing by Income, Ability, and Minority Status

\begin{tabular}{|c|c|c|c|c|c|}
\hline & (1) & (2) & (3) & (4) & (5) \\
\hline markup & 13.16 & 13.22 & 5.30 & 4.11 & 4.05 \\
\hline ability & -1.80 & -0.92 & -1.11 & -1.12 & -0.94 \\
\hline income & 0.03 & 0.03 & 0.02 & 0.02 & 0.03 \\
\hline minority status & -5.75 & -3.08 & -4.23 & -1.60 & -0.58 \\
\hline & (6) & (7) & (8) & (9) & $(10)$ \\
\hline markup & 2.66 & 3.09 & 2.86 & 0.75 & 2.77 \\
\hline ability & -1.06 & -1.06 & -1.14 & -1.09 & -1.96 \\
\hline income & 0.05 & 0.04 & 0.04 & 0.05 & 0.03 \\
\hline minority status & -0.51 & -0.50 & -0.33 & -0.27 & -0.11 \\
\hline
\end{tabular}

$\$ 210$ and $\$ 510$ for an increase of $\$ 10,000$ in family income among the 10 clusters. However, our estimates imply much more variation in pricing by ability and in the mark-ups. Average pricing by ability ranges between $\$ 920$ to $\$ 1960$ (for an increase in one standard deviation in ability). The largest discounts for minority status occur at the four highest ability schools, with discounts ranging from $\$ 1,600$ to $\$ 5,750$. Overall average mark-ups range between $3.5 \%$ and $35.5 \%$. We thus conclude that the most selective colleges have significant market power.

The average estimates mask price discrimination within colleges, which is more substantial. To illustrate the magnitude of these effects, we focus on Clusters 1 and 2 , which include the most selective colleges. Table 7 reports "local" market shares for non-minority students at the two most selective private colleges, with these market shares conditional on deciles for income and ability. ${ }^{24}$ Because colleges value student ability and price discriminate according to income and ability, the equilibrium exercise of market power will vary with student characteristics. The conditional market shares for high ability and high income students in these clusters are much larger than the overall unconditional market share, which is equal to 0.08. As a consequence the

\footnotetext{
${ }^{24}$ We use deciles, though localness can be defined using a finer or broader delineation.
} 
Table 7: Local Market Shares in Clusters 1 and 2

\begin{tabular}{ccccccccccc}
\hline \multicolumn{10}{c}{ income percentile } \\
\hline ability & 10 & 20 & 30 & 40 & 50 & 60 & 70 & 80 & 90 & 100 \\
\hline 10 & 0.00 & 0.00 & 0.00 & 0.00 & 0.01 & 0.00 & 0.01 & 0.00 & 0.02 & 0.00 \\
20 & 0.01 & 0.02 & 0.00 & 0.00 & 0.00 & 0.03 & 0.01 & 0.02 & 0.03 & 0.06 \\
30 & 0.01 & 0.00 & 0.00 & 0.00 & 0.02 & 0.05 & 0.00 & 0.04 & 0.03 & 0.05 \\
40 & 0.03 & 0.02 & 0.01 & 0.01 & 0.04 & 0.01 & 0.01 & 0.00 & 0.04 & 0.02 \\
50 & 0.02 & 0.01 & 0.00 & 0.02 & 0.02 & 0.06 & 0.03 & 0.04 & 0.09 & 0.11 \\
60 & 0.00 & 0.02 & 0.01 & 0.00 & 0.02 & 0.04 & 0.08 & 0.05 & 0.04 & 0.05 \\
70 & 0.00 & 0.01 & 0.01 & 0.02 & 0.06 & 0.05 & 0.03 & 0.10 & 0.08 & 0.08 \\
80 & 0.04 & 0.08 & 0.05 & 0.07 & 0.07 & 0.11 & 0.04 & 0.05 & 0.07 & 0.24 \\
90 & 0.08 & 0.07 & 0.04 & 0.07 & 0.13 & 0.20 & 0.10 & 0.07 & 0.20 & 0.23 \\
100 & 0.22 & 0.28 & 0.37 & 0.18 & 0.29 & 0.28 & 0.38 & 0.31 & 0.41 & 0.53 \\
\hline
\end{tabular}

Note: Table gives proportion of each income-ability percentile combination attending colleges in Cluster 1 or 2. Proportions are unweighted.

college has significantly larger local market power than is suggested by its overall market share.

The panels of Table 8 report predicted mark-ups by income and ability for majority students in Clusters 1 and 2. The values in the upper panel are the predicted markups over $E M C$ for a student at the midpoint of the cell, averaged over clusters 1 and 2 , the cells delineated by quintiles in these colleges calculated using our estimated admission thresholds. ${ }^{25}$ We see that these mark-ups increase precipitously with income, especially as students become relatively wealthy. A combination of higher willingness to pay as income rises and increasing market power of top tier colleges over richer students explains the latter. The mark-ups to the richest students of relatively low ability are very high, about $\$ 18,000$. For given income, mark-ups vary little with

\footnotetext{
${ }^{25}$ We use the estimated admission thresholds to calculate the minimum ability, the bottom value of the lowest ability quintile. Then we use the data for students above this minimum ability attending all colleges to compute ability quintile thresholds and income quintile thresholds, thus delineating the cells. The "midpoint" of each cell is the midpoint within the cell of ability and income. We have also calculated these tables using the predicted tuitions among the students in the data that attend clusters 1 and 2, with very similar results and available on request. The entries left blank in the table are because the number of students that actually attend within the cell, and thus used in estimation, are so low that the predictions are not credible.
} 
ability, except for the richest quintile where they fall substantially as ability increases (see the rightmost column). This reflects more competition for and thus less market power over high ability students that have enough income to be willing to pay for expensive colleges.

The lower panel calculates the more traditional mark-ups over marginal resource costs. That tuition is higher for low ability students and lower for high ability students is not purged in this version of the mark-up, and these mark-ups are then higher (lower) for low (high) ability students than in the upper panel. For high ability students without much income, these mark ups are negative, implying fellowships. Overall, we see that mark-ups and market power vary widely with student type.

Table 8: Predicted Mark-ups by Ability and Income Quintile, Clusters 1 and 2

\begin{tabular}{lccccc}
\hline & \multicolumn{5}{c}{ Mark-ups over Effective Marginal Cost } \\
\cline { 2 - 6 } ability $\backslash$ income & $0 \%-20 \%$ & $20 \%-40 \%$ & $40 \%-60 \%$ & $60 \%-80 \%$ & $80 \%-100 \%$ \\
\hline $0 \%-20 \%$ & - & 0.22 & 0.63 & 1.15 & 17.99 \\
$20 \%-40 \%$ & - & 0.23 & 0.64 & 1.16 & 17.56 \\
$40 \%-60 \%$ & - & 0.24 & 0.65 & 1.17 & 15.56 \\
$60 \%-80 \%$ & - & 0.25 & 0.66 & 1.18 & 12.66 \\
$80 \%-100 \%$ & 0 & 0.26 & 0.68 & 1.20 & 9.15 \\
\hline & - & Mark-ups over Marginal Resource Cost \\
ability $\backslash$ income & $0 \%-20 \%$ & $20 \%-40 \%$ & $40 \%-60 \%$ & $60 \%-80 \%$ & $80 \%-100 \%$ \\
\hline $0 \%-20 \%$ & - & 2.50 & 2.92 & 3.44 & 20.28 \\
$20 \%-40 \%$ & - & 1.89 & 2.30 & 2.82 & 19.22 \\
$40 \%-60 \%$ & - & 1.32 & 1.73 & 2.25 & 16.64 \\
$60 \%-80 \%$ & - & 0.68 & 1.09 & 1.61 & 13.10 \\
$80 \%-100 \%$ & -0.92 & -0.60 & -0.19 & 0.33 & 8.28 \\
\hline
\end{tabular}

We thus conclude that the most selective colleges have significant market power and charge significant mark-ups to students, especially for higher income, majority students. 


\section{Conclusions}

We have developed a new semi-parametric estimator for a model that explains price discrimination and market power in the U.S. market for higher education. We have implemented our new estimator using data from the NPSAS. We obtain reasonable estimates for all of the key parameters. Our empirical findings suggest that the majority of private colleges in the U.S. engage in pricing by income, ability, and minority status. A $\$ 10,000$ increase in family income increases tuition at private schools by an average of $\$ 210$ to $\$ 510$. A one standard deviation increase in ability decreases tuition by approximately $\$ 920$ to $\$ 1,960$ depending on the selectivity of the college. There are large and substantial discounts for minority students which range between approximately $\$ 110$ (at historically black colleges) and $\$ 5,750$ dollars. Average markups in colleges range between 3.5 and 33.5 percent, but vary substantially within colleges and are very large for high income students. There is much more heterogeneity in mark-ups within colleges than among colleges. Our analysis suggests that

highly selective colleges have significant market power, especially for high income, high ability, non-minority students.

We view the results of this paper as promising for future research. One might add private and state colleges with alternative objectives, perhaps focused on serving a segment of the population. Making endogenous state college pricing is of interest, a challenge being modeling public policy choice. Consideration of foreign students is of interest. In practice, there are small differences among the colleges within a cluster and colleges may engage in some limited competition for students that our model fails to capture.

One drawback of our modeling approach is that we do not allow for random coefficients in our utility specification. We do this primarily because of data limitations. It it is well know that it is rather difficult to identify the parameters of these distributions in a single cross-section without having access to second choice data as discussed in detail in Berry, Levinsohn, and Pakes (2004). We also do not observe 
large changes in the choice set over time. One could potentially use information of students that transferred between private and public schools to address these issues. Alternatively, it would be helpful to know the full portfolio of colleges that a students chooses at the application stage.

Finally, it would be useful to estimate a more comprehensive demand model that accounts for even more differentiation in the choice set. Estimating a model with a sufficiently large number of elements in the choice set would then allow researchers to implement the second stage of the estimator discussed in Appendix B and obtain reliable estimates for the remaining parameters of the model. 


\section{References}

Aguirregabiria, V. and Mira, P. (2002). Swapping the Nested Fixed Point Algorithm: A Class of Estimators for Discrete Markov Decision Models. Econometrica, 70 (4), 1519-1544.

Arcidiacono, P. (2005). Affirmative Action in Higher Education: How do Admission and Financial Aid Rules Affect Future Earnings?. Econometrica, 73 (5), 1477-1524.

Arcidiacono, P. and Nickolson, S. (2005). Peer Effects in Medical Schools. Journal of Public Economics, 89, 327-350.

Arcidiacono, P., Foster, G., Goodpaster, N., and Kinsler, J. (2012). Estimating Spillovers using Panel Data, with an Application to the Classroom. Quantitative Economics, 3 (3), 421-70.

Avery, C. and Levin, J. (2010). Early Admissions at Selective Colleges. American Economic Review, $100(6), 1-34$.

Bajari, P., Hong, H., and Nekipelov, J. K. D. (2010). Estimating static models of strategic interactions. Journal of Business and Economic Statistics, 28(4), 469-482.

Berry, S. (1994). Estimating Discrete-Choice Models of Product Differentiation. Rand Journal of Economics, 25(2), 242-262.

Berry, S., Levinsohn, J., and Pakes, A. (1995). Automobile Prices in Market Equilibrium. Econometrica, 63 (4), 841-890.

Berry, S., Levinsohn, J., and Pakes, A. (2004). Differentiated Products Demand Systems from a Combination of Micro and Macro Data: The New Vehicle Market. Journal of Political Economy, 112, 68-104.

Bettinger, E., Long, B. T., Oreopolous, P., and Sanbonmatsu, L. (2012). Determinants of College Major Choices: Identification from an Information Experiment. Results From The HR Block FAFSA Experiment. Quarterly Journal of Economics, 127 (3), 1-38.

Betts, J. and Morell, D. (1999). The Determinants of Undergraduate GPA: The Relative Importance of Family Background, High School Resources, and Peer Group Effects. Journal of Human Resources, 107, 797-817.

Boisjoly, J., Duncan, G. J., Kremer, M., Levy, D. M., and Eccles, J. (2006). Empathy or Antipathy? The Impact of Diversity. The American Economic Review, 96 (5), 1890-1905.

Bordon, P. and Fu, C. (2015). College-Major-Choice to College-Then-Major-Choice. Review of Economic Studies, 82, 1247-88. 
Brock, W. and Durlauf, S. (2001). Discrete Choice with Social Interactions. Review of Economic Studies, 68 (2), 235-260.

Carrell, S. E., Fullerton, R. L., and West, J. E. (2009). Does Your Cohort Matter Measuring Peer Effects in College Achievement. Journal of Labor Economics, 27(3).

Cestau, D., Epple, D., and H.Sieg (2017). Admitting Students to Selective Education Programs: Merit, Profiling, and Affirmative Action. Journal of Political Economy, forthcoming.

Chade, H., Lewis, G., and Smith, L. (2014). Student Portfolios and the College Admissions Problem. Review of Economic Studies, 81, 971-1002.

Dynarski, S. (2002). The behavioral and distributional implications of aid for college. American Economic Review, 92 (2), 279-85.

Epple, D. and Romano, R. (1998). Competition Between Private and Public Schools, Vouchers and Peer Group Effects. American Economic Review, 88, 33-63.

Epple, D. and Romano, R. (2008). Educational Vouchers and Cream Skimming. International Economic Review, 49, 1395-1435.

Epple, D. and Romano, R. (2010). Peer Effects in Education: a Survey of the Theory and Evidence. In Benhabib, J., Bisin, A., and Jackson, M. (Eds.), Handbook of Social Sciences, Vol 1b, pp. 1053-1163. Elsevier Science.

Epple, D., Romano, R., Sarpca, S., and Sieg, H. (2017). A General Equilibrium Analysis of Access to Higher Education in the U.S.. Journal of Public Economics, forthcoming.

Epple, D., Romano, R., and Sieg, H. (2003). Peer Effects, Financial Aid, and Selection of Students into Colleges. Journal of Applied Econometrics, 18 (5), 501-525.

Epple, D., Romano, R., and Sieg, H. (2006). Admission, Tuition, and Financial Aid Policies in the Market for Higher Education. Econometrica, 74(4), 885-928.

Fillmore, I. (2016). Price discrimination and public policy in the U.S. college market. Working Paper.

Foster, G. (2006). Its not your peers, and its not your friends: Some progress toward understanding the educational peer effect mechanism. Journal of Public Economics, 90, 1455-75.

Fu, C. (2014). Equilibrium Tuition, Applications, Admissions and Enrollment in the College Market. Journal of Political Economy, 122 (2), 225-81.

Heckman, J. (1979). Sample Selection Bias as a Specification Error. Econometrica, 47 (1), 153-161. 
Hickman, B. (2013). Pre-college Human Capital Investment and Affirmative Action. Working Paper.

Hotz, J. and Miller, R. (1993). Conditional Choice Probabilities and Estimation of Dynamic Models. Review of Economic Studies, 60, 497-529.

Hoxby, C. (1997). How the Changing Market Structure of U.S. Higher Education Explains College Tuition. NBER Working Paper 6323.

Hoxby, C. (1999). Benevolent Colluders? The Effect of Antitrust Action on College Financial Aid and Tuition. NBER Working Paper 7754.

Kapor, A. (2016). Distributional Effects of Race-Blind Affirmative Action. Working Paper.

Kremer, M. and Levy, D. (2008). Peer Effects and Alcohol Use among College Students. Journal of Economic Perspectives, 22(3), 189-206.

Lyle, D. S. (2007). Estimating and Interpreting Peer and Role Model Effects from Randomly signed Social Groups at West Point. Review of Economics and Statistics, 1-20.

Lyle, D. S. (2009). The Effects of Peer Group Heterogeneity on the Production of Human Capital at West Point. American Economic Journal: Applied Economics, 1(4), 69-84.

MacLeod, B. and Urquiola, M. (2015). Reputation and school competition. American Economic Review, 105(11), 3471-3488.

Manski, C. (1993). Identification of Endogenous Social Effects: The Reflection Problem. Review of Economic Studies, 60, 531-542.

McFadden, D. (1974). The Measurement of Urban Travel Demand. Journal of Public Economics, 3, 303-328.

McPherson and Schapiro, M. O. (2006). U.S. Higher Education Finance. In Handbook of Education. Elsevier North Holland.

Moffitt, R. (2001). Policy Interventions, Low-level Equilibria, and Social Interactions. In Social Dynamics. MIT Press.

Rothschild, M. and White, L. (1995). The Analytics of the Pricing of Higher Education and Other Services in Which the Customers are Inputs. Journal of Political Economy, 103, 573-623.

Sacerdote, B. (2001). Peer Effects with Random Assignment: Results from Dartmouth Roommates. Quarterly Journal of Economics, 116(2), 681-704. 
Sacerdote, B. (2011). Peer effects in education: How might they work, how big are they and how much do we know thus far?. In Hanushek, E. e. a. (Ed.), Handbook of Education 3, pp. 249-277. Elsevier Science.

Stinebrickner, R. and Stinebrickner, T. R. (2006). What can be learned about peer effects using college roommates? Evidence from new survey data and students from disadvantaged backgrounds. Journal of Public Economics, 90, 1435-54.

van der Klaauw, W. (2002). Estimating the Effect of Financial Aid Offers on College Enrollment: A Regression Discontinuity Approach. International Economic Review, 43 (4), 1249-87.

Wiswall, M. and Zafar, B. (2015). Determinants of College Major Choices: Identification from an Information Experiment. Review of Economic Studies, 82 (2), 791-824.

Zimmerman, D. (2003). Peer Effects in Higher Education: Evidence From a Natural Experiment. Review of Economics and Statistics, 85, 9-23. Working Paper. 


\section{A Construction of the Ability Measure and Abil- ity Thresholds}

We measure ability by predicting students' first-semester GPA as a function of their high school GPA, ACT score (or SAT score converted to ACT score), gender, major, and college choice.

The predicted GPA for student $i$ at school $j$ in discipline $d$ is given by:

$G P A_{i j d}=\beta_{0}+\beta_{1} H S G P A_{i}+\beta_{2} A C T_{i}+\beta_{3} H S G P A_{i} * A C T_{i}+\beta_{4}$ female $_{i}+\beta_{j}+\beta_{d}+\epsilon_{i j d}$

where $\beta_{j}$ represents a college fixed effect and $\beta_{d}$ represents a major fixed effect (12 majors, humanities omitted). Using a sample of approximately 5,000 white students at 4-year public or private universities, we obtain the following prediction (for a generic discipline at a generic school as these fixed effects and the intercept are dropped):

$\widehat{G P A_{i}}=-3.184 H S G P A_{i}+-2.559 A C T_{i}+0.918 H S G P A_{i} * A C T_{i}+21.961$ female $_{i}$

The $R^{2}$ for the estimated model (including fixed effects) is 0.9342. After clustering, we then standardize the ability measure to have standard deviation 1 and mean 0.415 , such that all schools have $\theta_{j} \geq 0$.

There are no explicit ability admission thresholds in the data. We estimate these thresholds using all students except a small number of "legacy students" at some of the most selective universities. ${ }^{26}$ We construct these by taking the first percentile predicted GPA at any public college with at least ten non-minority students (as our model implies different admission thresholds for minority students), and applying

\footnotetext{
${ }^{26}$ Legacy students are believed to contribute additional value to the school (perhaps through alumni donations), and thus are subject to different admission criteria. Due to this unobserved characteristic, they have a lower net marginal cost for the school and may be admitted despite lower ability. Legacy students are identified off the empirical CDF of ability within a school-they precede the lowest flat region in the CDF. In support of our hypothesis, such students tend to be non-minority students with high family income.
} 
the minimum within cluster as the cluster admission threshold. Any students below this threshold presumably have characteristics desirable to a college, and so these students are "bumped up" to the threshold predicted GPA. This new measure is used in admission and tuition estimation for all colleges. We considered other approaches to construct these admission thresholds, and found that the main results reported in this paper are not sensitive to the specifics discussed above.

\section{B Identification and Estimation of the Remaining Parameters of the Model}

For certain applications, knowledge of the level of $\omega, \gamma$, and $\kappa$ is useful. This section discusses how to identify and estimate the levels of these parameters using a modified version of the estimator suggested by Berry (1994).

Two additional challenges to estimation are present that are typically not encountered in standard demand analysis. First, the potential choice set of a student is unobserved by the econometrician. Our model implies, however, that both private and public schools use minimum-ability threshold rules to determine admission functions. These arise because both private and public colleges face binding price maxima that lead to minimum ability admission thresholds. We observe attendance in equilibrium and as a consequence can estimate minimum admission thresholds using order statistics. This allows us to characterize the relevant choice set for each student in the sample.

Second, private colleges engage in third-degree price discrimination. Hence institutional aid and net tuition policies of all private colleges are functions of income and ability as long as the price maximum is not binding. A key challenge encountered in estimation is that the institutional aid is only observed at the college that is attended in equilibrium. The econometrician does not observe the financial aid packages and, hence the net tuition, that were offered by the colleges that also admitted the stu- 
dent, but were ultimately rejected by the student. As a consequence, we cannot directly evaluate the conditional choice probabilities for each student. However, we can consistently estimate the institutional aid functions of each college type using nonparametric techniques such as kernel or sieve estimators. Given these consistent estimators we then can compute the conditional choice probabilities of each student.

Consider the full sample of all students, including those students that attend private colleges and that pay the posted price as well as students attending public colleges and universities.

We can construct the minimum ability threshold for each college, by computing the minimum ability of the students. Let our estimator be denoted by $b_{j m}^{\min }$. We can then identify the choice set for all students as follows:

$$
J_{a}(m, s, b)=\left\{s \mid b \geq b_{s m}^{m i n}\right\} \cup\left\{o \in S \backslash\{s\} \mid b \geq b_{o m}^{m i n}\right\} \cup\left\{j \in P \mid b \geq b_{j m}^{m i n}\right\} \cup\{0\}
$$

The first and second sets are, respectively, the in-state public colleges and the out-of state public colleges admitting the student. The third set denotes the set of all private colleges to which the student is admitted, and the last set is the outside option.

We then non-parametrically estimate the prices for each student at each college to which the student was admitted based on the observed tuition levels, using a local smoothing quadratic polynomial that uses a bin width of half of all points for each local estimation. Let us denote these estimates by $\hat{p}_{s j i}^{n p}$.

For private colleges, we use a local polynomial smoothing estimator to estimate the tuition function. The polynomial constructs a non-parametric estimate of tuition based on ability and income, and interpolates only where the observed data span. That is, if we observe an individual with a similar ability and income attending the college with a given tuition, the LOESS estimator calculates a polynomial relationship among tuition, ability, and income within the relevant bandwidth and predicts tuition locally. However, the resulting admission set-where a tuition can be predicted-is really a combination of admission and matriculation. Thus, many lower quality col- 
leges would appear to reject high-quality applicants, because no such applicants are observed at the college. Hence we assume that if a college accepts an individual with ability $b^{\text {min }}$, it accepts all individuals where $b_{i} \geq b^{\text {min }}$. Then, we extrapolate the local polynomial to such individuals to ensure all admitted individuals have a valid first-stage tuition offer.

Substituting the nonparametric estimates of the tuitions into the conditional choice probabilities, we obtain

$$
\hat{r}_{j i}=\frac{\left[\left(y_{i}-\hat{p}_{s j i}^{n p}-L+A_{s_{i}, j}\left(y_{i}\right)\right) q_{j}\right]^{\alpha}}{\sum_{k \in J_{a}\left(m_{i}, s_{i}, b_{i}\right)}\left[\left(y_{i}-\hat{p}_{s k i}^{n p}-L+A_{s k}\left(y_{i}\right)\right) q_{k}\right]^{\alpha}}
$$

The quality levels for each school are determined by the fixed point of the following mapping:

$$
\tilde{q}_{j}=q_{j}+\ln \left(s_{j}^{N}\right)-\ln \left(s_{j}(q)\right) \quad j=1, \ldots, J-1
$$

where: $q_{j}$ is initial guess of the quality, $s_{j}^{N}$ is the average empirical market share of college $j$ observed in the data, and $s_{j}(q)$ is the predicted average market share using the initial guess about the vector of qualities:

$$
s_{j}(q)=\frac{1}{N} \sum_{i=1}^{n} \hat{r}_{j i}
$$

We can identify $q_{j}$ 's for each college, subject to a normalization such as $q_{1}=1$. The normalization of quality is necessary since market shares add up to one.

Using the fact that $q_{j}=\theta_{j}^{\gamma} I_{j}^{\omega} \Gamma_{j}^{\kappa} e^{u_{j}}$ we obtain the the following regression model:

$$
\ln \left(q_{j} / q_{1}\right)=\omega\left(\frac{\gamma}{\omega} \ln \left(\theta_{j}\right)+\frac{\kappa}{\omega} \ln \left(\Gamma_{j}\right)+\ln \left(I_{j}\right)-\frac{\gamma}{\omega} \ln \left(\theta_{1}\right)-\frac{\kappa}{\omega} \ln \left(\Gamma_{1}\right)-\ln \left(I_{1}\right)\right)+u_{j}-u_{1}
$$

Define

$$
w_{j}=\frac{\gamma}{\omega} \ln \left(\theta_{j}\right)+\frac{\kappa}{\omega} \ln \left(\Gamma_{j}\right)+\ln \left(I_{j}\right)-\frac{\gamma}{\omega} \ln \left(\theta_{1}\right)-\frac{\kappa}{\omega} \ln \left(\Gamma_{1}\right)-\ln \left(I_{1}\right)
$$


and note that $w_{j}$ is known at this point. Rewriting equation (34) as

$$
\ln \left(q_{j} / q_{1}\right)=\omega w_{j}+u_{j}-u_{1}
$$

and hence $\omega$ can be estimated using a simple ratio estimator. This estimator is consistent despite the fact that $w_{j}$ and $u_{j}-u_{1}$ may not be independent because the regression above does not have an intercept. Note that the last step of the estimator requires a large number of colleges or preferably multiple markets.

When we implement the last two stages of our estimator, we obtain point estimates for $\omega$ that range between 0.027 and 0.033 . Unfortunately, our sample size is too small $(J=15)$ to obtain precise estimates. 